\title{
Uma análise histórica a partir da Stadtplatz (Centro histórico) de Itapiranga e sua relação com o turismo cultural
}

\section{A historical analysis from Itapiranga's Stadtplatz and its relationship with cultural tourism}

\section{Douglas Orestes Franzen}

Docente da Unidade Central De Educação Faem Faculdade - UCEFF, Itapiranga/SC, Brasil E-mail: douglas@uceff.edu.br

\section{Claudine Machado Badalotti}

Mestre em História pela Universidade de Passo Fundo - UPF, Passo Fundo/RS, Brasil

E-mail: arquiteta.claudine@gmail.com

\section{Gabriel Carpes de Chaves}

Graduado em Arquitetura e Urbanismo pela Unidade Central De Educação Faem Faculdade UCEFF, Itapiranga/SC, Brasil

E-mail: gabrielchaves96@hotmail.com 


\begin{abstract}
RESUMO
O texto propõe fazer uma reflexão sobre a história da colonização Porto Novo (Itapiranga-SC) e relacionar esse contexto com a formação do Stadtplatz (Centro Histórico) na cidade. O objetivo é apresentar elementos referenciais arquitetônicos representados por edificações históricas que estão presentes na paisagem a partir do núcleo fundacional da cidade. A partir disso, a análise apresenta uma proposta de vinculação desse centro histórico com a dinâmica do turismo em Itapiranga buscando apresentar referenciais disponíveis para a constituição de práticas turísticas e culturais tendo o centro histórico como elemento gerador no contexto local.
\end{abstract}

Palavras-chave: Itapiranga. Centro Histórico. Turismo Cultural.

\title{
ABSTRACT
}

The text proposes to reflect on the history of colonization Porto Novo (Itapiranga) and relate this context to the formation of Stadtplatz (Historic Center) in the city. The objective is to present architectural reference elements represented by historical buildings that are present in the landscape from the founding nucleus of the city. From this, the analysis presents a proposal for linking this historical center with the tourism dynamics in Itapiranga, aiming to present references available for the constitution of tourist and cultural practices, having the historical center as a generating element in the local context

Keywords: Itapiranga. Historic Center. Cultural Tourism. 


\section{INTRODUÇÃO}

O centro histórico constitui um elemento referencial para o espaço urbano, pois sintetiza a dinâmica da ocupação e desenvolvimento da cidade. Ele é um marco territorial que se conecta com o contexto urbano através da vinculação histórica e identitária. A partir do centro histórico podem-se constituir representações da cidade para a constituição de políticas de gestão urbana e do patrimônio histórico. É a partir dessa reflexão que o texto busca contextualizar a relevância do centro histórico (Stadtplatz) de Itapiranga-SC partindo de alguns marcos referenciais da paisagem urbana, tendo como base as edificações históricas presentes em determinado contexto territorial.

A análise se justifica tendo como referência o núcleo gerador da cidade de Itapiranga e sua vinculação com a identidade histórica local a partir da referência comunitária igrejaescola-clube e sua relevância para a identidade cultural. O centro histórico aqui entendido expressa elementos chave do processo de formação da identidade cultural comunitária ao longo do desenvolvimento histórico de Itapiranga. A partir deles que o texto propõe a delimitação territorial de um centro histórico e propõe uma reflexão sobre a importância que ele possui perante a cidade e também como elemento fomentador de práticas de turismo cultural.

A metodologia aplicada consiste numa relação teórico empírica para conectar patrimônio cultural com a história de Porto Novo (Itapiranga-SC) na formação da Stadtplatz, o centro histórico da cidade. Para tanto foi realizado um mapeamento de edificações históricas de caráter comunitário e social como igrejas, sedes sociais, escolas e edifício de referência pública. Edificações residenciais e privadas foram desconsideradas para a presente análise apesar de terem uma conexão com a abordagem proposta.

Para o desenvolvimento da análise primeiramente se considerou a história da colonização local no intuito de subsidiar a discussão sobre a identidade cultural e da relevância das edificações para a memória local. A partir desse elemento histórico foi possível mapear territorialmente o centro histórico de Itapiranga a partir do núcleo fundacional da Stadtplatz, que é apresentado aqui como um conceito referencial de uma área.

A análise considera a dimensão histórica das edificações e sua disposição no centro histórico, visando a partir delas pensar propostas de fomento ao turismo histórico e cultural. Entende-se que a partir do momento que determinado elemento se potencializa economicamente a partir do turismo, a sociedade local e as políticas públicas passam a tratar o centro histórico com um olhar diferenciado na dinâmica do planejamento e gestão urbana. 
Por isso, o texto busca evidenciar a relevância do centro histórico para Itapiranga a partir de um olhar das edificações ainda presentes no núcleo fundacional da cidade diante das inúmeras que já se perderam ou se deterioraram. Assim, a partir da delimitação territorial do centro histórico a partir do núcleo fundacional da cidade elencamos seis edificações presentes nesse espaço e que tem caráter relevante para a comunidade local: o Museu Comunitário Almiro Theobaldo Müller, o Clube Kolping, o Hospital Sagrada Família, a antiga Escola São Vicente, a Igreja Matriz da Paróquia São Pedro Canísio e o Museu do Cooperativismo.

\section{A COLONIZAÇÃO DE ITAPIRANGA}

O projeto de colonização Porto Novo foi idealizado pela Sociedade União Popular, denominada em alemão de Volksverein, instituição que coordenou a implantação de outras colônias alemãs no Rio Grande do Sul, vinculado aos Padres Jesuítas, com o objetivo de implantar no extremo oeste de Santa Catarina uma nova fronteira agrícola e social. O empreendimento foi financiado pela Cooperativa de Crédito Sparkasse, e fundado oficialmente no ano de 1926. Já no ano de 1928, a colonização recebeu o nome de Itapiranga, atual nome do município, gerando mais tarde a emancipação dos municípios de Tunápolis e São João do Oeste.

A Volksverein für die deutschen Katholiken von Rio Grande do Sul não era necessariamente uma empresa de colonização. Era, na verdade, uma entidade associativa fundada para dar assistência à população de descendência alemã e católica no Sul do Brasil. Essa associação chegou a ter no período da Primeira Guerra Mundial cerca de oito mil associados.

A característica do empreendimento Porto Novo era de aceitar somente migrantes que fossem de origem germânica e católica. Nesse sentido, famílias originárias das colônias do Rio Grande do Sul e de Santa Catarina compraram terras nessa colônia em busca de novas fronteiras agrícolas, onde as terras já estavam subdivididas e esgotadas. Da mesma forma, adquiriram terras em Porto Novo, imigrantes que fugiam das duras condições de vida em vilarejos europeus, expulsos pelas atrocidades da guerra, pela perseguição étnico-política, ou pelas péssimas condições de vida e de trabalho lá existentes (Werle, 2011).

O processo de fundação da colônia Porto Novo promoveu a transferência de um local para outro de uma bagagem cultural alicerçada em sujeitos através de uma estrutura socioeconômica e cultural que esses sujeitos trataram de transportar de seu local de origem através das instituições, organizações e no seu estilo de vida. Essa bagagem cultural e social 
dos migrantes adaptou-se ao meio, às limitações do relativo isolamento percebido no período no extremo oeste catarinense, fazendo com que os sujeitos construíssem uma nova identidade, com fortes traços herdados das colônias de origem, mas com uma nova dinâmica cultural (Mayer \& Neumann, 2016).

De maneira geral podemos sintetizar a origem dos colonizadores de Porto Novo sob duas perspectivas. A primeira das famílias imigrantes originárias da Alemanha e de colônias alemãs europeias como da região da Bessarábia, os Deutschrumänen, e do vale do Rio Danúbio na Iugoslávia, os Donauschwaben (Jungblut, 2000). Essas famílias deixaram a Europa motivadas por questões econômicas, políticas e territoriais do cenário conturbado das décadas de 1920 e 1930, sendo significativo o número de imigrantes que se estabeleceram em Porto Novo, principalmente por intermédio de agenciadores e de influência dos padres jesuítas e da Volksverein nesses processos imigratórios. A segunda, composta de famílias descendentes da primeira geração de imigrantes alemães do século XIX que se estabeleceram nas colônias velhas do Rio Grande do Sul e de Santa Catarina. Essas famílias já estavam adaptadas ao território e ao clima brasileiro e deixaram suas regiões de origem motivadas principalmente pela questão fundiária e a degradação das relações produtivas, pela escassez de terras e limitações produtivas (Roche, 1969). Além disso, muitas famílias compraram terras em Porto Novo motivados pela propaganda de prosperidade, fartura territorial, de solo e de riqueza natural, além do atrativo étnico e cultural do catolicismo e da germanidade (Mayer, 2018).

Na concepção de Woortmann (1994) a migração de uma colônia velha para uma colônia nova seria um processo de dispersão que minimizaria a pressão demográfica nas primeiras, "fazendo com que o mesmo processo que produz a colônia nova reproduza a colônia velha" (Woortmann, 1994, p. 182). Ou seja, nesse processo migratório se reconfiguram conhecimento e vivências simbólicas que estruturam padrões de vida e de compreensões espaço-temporais.

Fato que se pretende destacar é de que havia uma intencionalidade conjectural em se formatar uma colonização homogênea étnica e cultural no local. Essa preocupação já vinha de longa data e o tema se acalorava entre lideranças católicas do Volksverein, elemento que se fundia na preocupação em constituir laços matrimoniais entre famílias católicas e alemãs, manutenção de costumes e tradições consideradas de índole cristã, relações comunitárias e sociais que conservassem padrões sociais tradicionais em oposição ao padrão moderno e heterogêneo então em voga no Brasil (Werle, 2011). Essa preocupação com a homogeneidade étnica e confessional direcionou o desenvolvimento da colonização Porto Novo nas primeiras 
décadas, modelo que acabou caindo em desuso a partir da década de 1950 pela gradual venda de todos os lotes por parte da colonizadora e pela nova conjuntura brasileira que se desenhou no pós-guerra em termos de economia, sociedade e política. Mas é preciso destacar de que esse padrão germânico e católico foi determinante na formatação de um sistema cultural, elemento que constituiu a base de identidade germânica presente na cultura local e que se manifesta na conjuntura urbana que se pretende analisar.

\section{A FORMAÇÃO DA STADTPLATZ}

Para compreender o desenvolvimento do espaço urbano de Itapiranga, é preciso compreender a influência que o Rio Uruguai teve nesse processo. O leito do rio formatou o desenho urbano e delineou o princípio do espaço urbano. O núcleo urbano que aqui denominaremos de centro histórico se configurou às margens do rio e a partir dali se desenvolveu com o passar dos anos. Através do leito do Rio Uruguai, pode-se comprovar que este foi o principal responsável por gerar a rua em sua forma urbana linear e paralela ao longo do rio, dando continuidade as futuras vias paralelas e perpendiculares neste mesmo sentido (Mazzardo, 2017).

A denominação da Stadtplatz será compreendida aqui como o núcleo central do espaço urbano de Itapiranga a partir do seu desenvolvimento a partir de 1926. Como não se tem referências de um mapa urbano produzido no início da colonização, utilizaremos de fotografias para compreender o espaço no qual se desenvolveu o núcleo da vila e consequentemente o centro histórico embrionário do espaço urbano. 


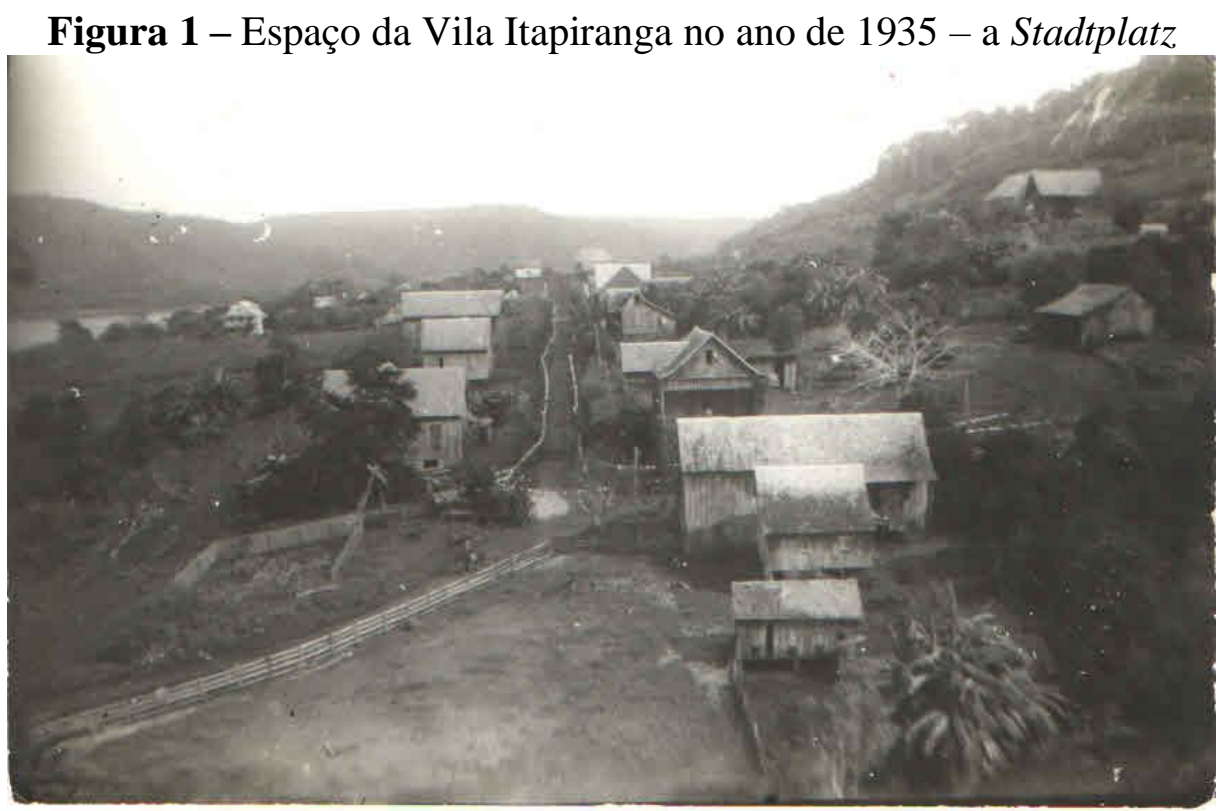

Fonte: Museu Comunitário Almiro Theobaldo Müller ${ }^{1}, 2019$.

A figura 1 sintetiza o traçado da rua central da vila Itapiranga, o que atualmente é a Rua do Comércio. Nela podemos perceber o núcleo embrionário do espaço urbano e o desenho da disposição das primeiras edificações da vila no ano de 1935. Na Imagem 02 percebemos esse mesmo centro histórico no ano de 1945 sob uma olhar da paisagem a partir do leito do Rio Uruguai, tendo como destaque o Clube Kolping (1), a antiga igreja em madeira e a primeira escola da vila (2).

Figura 2 - Perspectiva do centro histórico em 1945

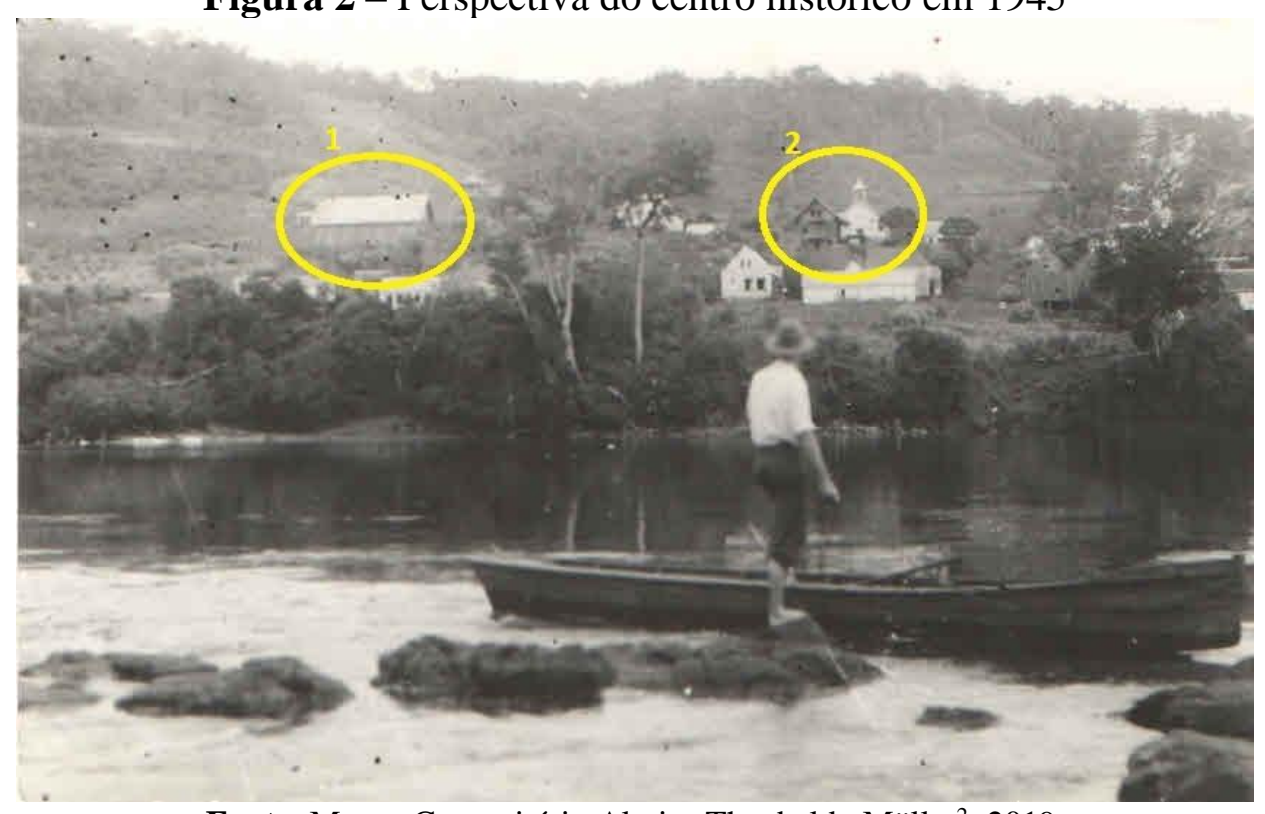

Fonte: Museu Comunitário Almiro Theobaldo Müller², 2019.

\footnotetext{
${ }^{1}$ Site do Museu https://turismo.itapiranga.sc.gov.br/equipamento/index/codEquipamento/7211

${ }^{2}$ Site do Museu https://turismo.itapiranga.sc.gov.br/equipamento/index/codEquipamento/7211
} 
A partir dessas imagens e com base no estudo de Mazzardo (2017) delimitamos um território que conceberemos como o núcleo histórico de Itapiranga, o núcleo fundacional da cidade a partir de 1926. A partir de uma perspectiva atual do espaço urbano de Itapiranga, propomos um recorte espacial do que concebemos como sendo o Stadtplatz:

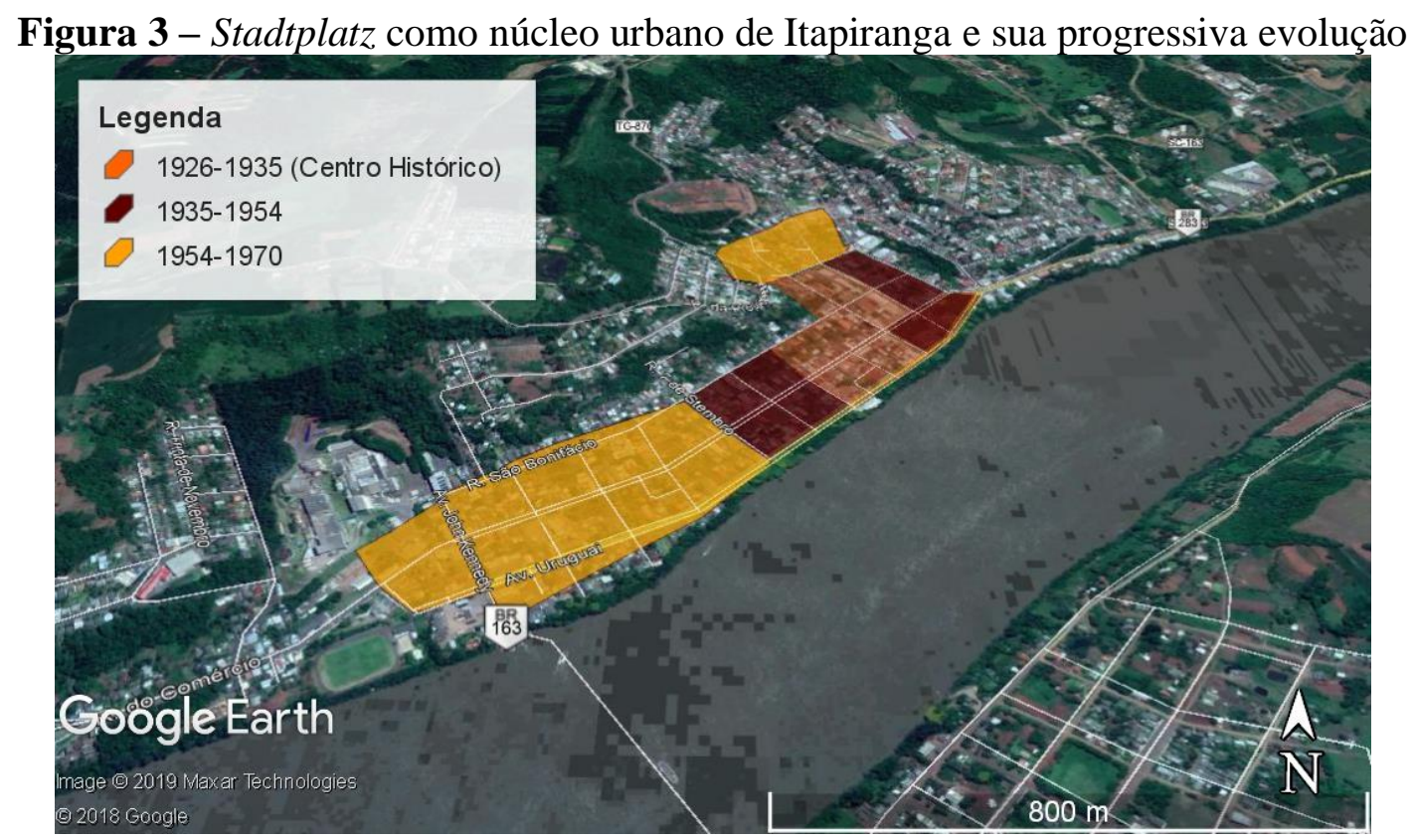

Fonte: Google Earth, adaptado pelos autores, 2019.

Esse conceito de Stadtplatz no processo de evolução urbana parece ter se replicado em outras regiões de colonização alemã no Sul do Brasil. Seyferth (2011), a partir dos estudos da colonização do Vale do Itajaí em Santa Catarina, aponta que esse modelo também era recorrente naquela região. As linhas coloniais, ou picadas, eram demarcadas observando prioritariamente os cursos de água, e "convergiam para uma via principal a partir do local do povoado, geralmente demarcado com lotes urbanos, destinados a comerciantes, artesãos, prestadores de serviços, administração, igrejas, escolas, etc.” (Seyferth, 2011, p. 13).

$\mathrm{Na}$ colonização de Itapiranga um elemento deve ser vislumbrado para entendermos a formação do núcleo urbano na vila de Itapiranga. Desde o princípio da colonização dois referenciais se formaram como ponto de entrada das famílias colonizadoras que chegavam pelo Rio Uruguai, desembarcando nos portos da Linha Sede Capela e de Itapiranga. Essa bipolaridade logo engendrou uma disputa simbólica entre as duas linhas coloniais para se tornarem a sede da colonização, aspecto muito recorrente na história local e dimensionado nas memórias da pioneira Maria Rohde, que denominou as duas vilas de núcleo urbano inferior e superior (Rohde, 2011). A título de curiosidade, a construção da Casa Paroquial na Vila Itapiranga em 1932 pode ser um dos elementos a serem considerados para entender os 
motivos do núcleo urbano se desenvolver mais consistentemente em Itapiranga em detrimento da Linha Sede Capela. A partir da Casa Paroquial a vila Itapiranga se tornou uma referência religiosa para a colonização, aspecto significativo se considerada a relevância da simbologia religiosa para os primórdios da colônia.

Outros elementos podem ser considerados para compreendermos o desenvolvimento da Stadplatz. Podemos citar a criação em 1932 da Cooperativa de Crédito Rural União Popular que instalou sua sede em Itapiranga, sendo a primeira cooperativa de crédito do Estado de Santa Catarina. Já a partir da emancipação de Itapiranga em 1954 vários outros elementos se agregam ao espaço e que estimulam a expansão urbana de Itapiranga, como a instalação da Prefeitura Municipal, a construção do frigorífico Safrita em 1962 e a implantação da Comarca de Itapiranga em 1973.

\section{O CENTRO HISTÓRICO - ALTSTADT}

O processo de preservação do patrimônio histórico é uma caminhada muito recente no Brasil, aspecto que se reflete nas modestas e tímidas políticas de preservação e restauração se considerarmos a amplitude de nossa história e de nosso território. No entanto, a cultura da preservação dos espaços históricos e da valorização da memória é um aspecto que vem ganhando notoriedade nas políticas públicas e atenção da iniciativa privada principalmente pelo seu potencial comercial e turístico. Nesse sentido, a história e a memória se tornam instrumentos de criação de produtos turísticos e mercadológicos, que se reflete em mercadorias, na criação de marcas de empresas e produtos, e na estruturação de espaços de geração de riqueza e renda advinda da produção histórica e cultural.

Nessa dimensão entendemos de que o patrimônio é simbólico como valor de herança cultural, não sendo necessariamente tombado pelo poder público, mas assimilado e percebido pela população como um valor de identidade histórica e de memória. O reconhecimento de um valor patrimonial se manifesta na ideia de que a arquitetura ou um espaço de valor de memória ou de paisagem, se integra ao meio e se aproxima do cotidiano das pessoas que ali vivenciam suas relações sociais e culturais. Dessa forma, um espaço se constitui pelo valor que simboliza e pela identidade cultural que reflete, e, para além de ser restaurado e preservado, precisa ser revitalizado para se adequar ao contexto do presente. Revitalizar um espaço, um ambiente ou uma edificação é estimular a sociedade a fazer uso de determinado bem patrimonial, reconhecendo-o como próprio da sua cultura e a partir desse reconhecimento entender o seu significado e a urgência de preservá-lo (Scocuglia, 2004). 
Mas como dimensionar a ideia de um centro histórico? Primeiramente é preciso vislumbrar a ideia de que centro histórico é um conceito, ou seja, um elemento vinculado a uma delimitação espaço-temporal. Essa delimitação está conectada ao ato de incluir e de excluir, mais especificamente, de delimitar um território com características arquitetônicas e simbólicas com um padrão caracterizante que exprime uma representação histórica e de valor de memória e identidade. O desafio contemporâneo nos debates sobre a preservação dos espaços históricos e patrimoniais da cidade está presente no debate de ultrapassar a mera compreensão de centro histórico para a noção de cidade histórica.

Nesse sentido, Trusiani (2004, p. 105), entende que,

A passagem do centro histórico à cidade histórica, portanto, não significa homogeneizar tudo o que existe e tratar diversamente o que está fora do seu perímetro, mas significa reconhecer as diferenças que caracterizam as diversas partes; saber descrevê-las e conservá-las, e simultaneamente sugerir, onde necessário, as modificaçõos compatíveis com essas diferenças.

A partir disso o estudo propõe uma delimitação do que se pode conceber como o centro histórico de Itapiranga a partir das edificações existentes em determinado perímetro a partir do núcleo originário da cidade. Essa área foi delimitada tendo como referência as edificações históricas e os espaços de relevância de memória e de identidade, como é o caso da Praça do Imigrante (local onde foi celebrada a primeira missa em 1926).

Delimitar um espaço a partir do referencial histórico envolve estipular parâmetros e referências que servem de embasamento para a compreensão espacial do espaço urbano. Para tal, fim é preciso ter referenciais. Propõe-se a partir dessa reflexão, que em determinado conjunto espacial existem atualmente referenciais arquitetônicos e paisagísticos que oferecem subsídios para a criação de um conceito de centro histórico de Itapiranga. Não é nosso objetivo valorizar esse espaço em detrimento do conjunto da cidade, sendo essa uma preocupação que gera inquietamento e sinaliza uma atenção no sentido de propiciar uma sobrevalorização de determinado espaço na cidade. 
Figura 4 - Delimitação territorial do Centro Histórico a partir do núcleo fundacional

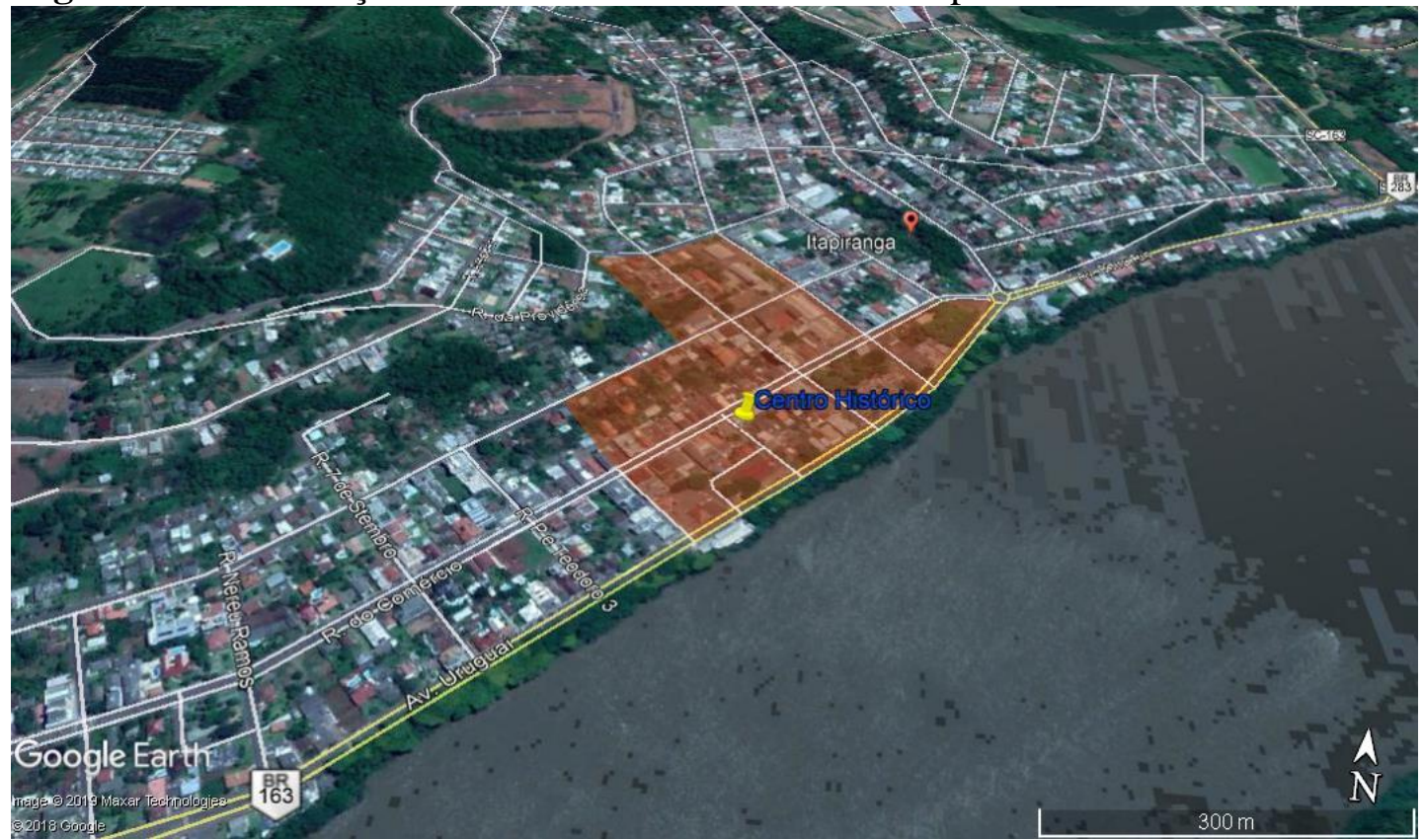

Fonte: Google Earth. Adaptado pelos autores, 2019.

O que se pretende aqui é oferecer uma possibilidade de compreensão de um espaço a partir de um núcleo fundacional da cidade de Itapiranga, e que esse espaço apresenta atualmente um referencial de elementos arquitetônicos que podem servir de subsídio para práticas de fomento ao turismo histórico e cultural. Não se pode desconectar o centro histórico do contexto da cidade, eles são ambivalentes e se conectam pelas vivências cotidianas. O que se pretende é estimular a consciência de que no centro histórico se preservam edificações, espaços de memória e praças que remetem a uma identidade histórica e cultural.

A própria dimensão do centro da cidade historicamente esteve vinculada à dimensão de uma centralidade de serviços, de conexões e relações. Como um gérmen, um nódulo central, para onde muitas atividades do espaço urbano confluem e se irradiam. Na visão de Silva (2014, p. 317) é no centro da cidade que "as temporalidades se manifestam pela memória das pessoas usualmente agregada à matéria da arquitetura”. 


\section{O CENTRO HISTÓRICO E A IDENTIDADE HISTÓRICA E CULTURAL}

O centro histórico aqui compreendido abrange um espaço onde se localizam edificações, espaços e monumentos que constituem um núcleo urbano gerador e dessa forma remetem a uma construção histórica da paisagem local. Em que medida essa identidade é constituída e simbolizada está ligada à dimensão de sua representatividade cultural e histórica para a população local, o que formata o conceito de patrimônio histórico e cultural. Zanirato (2018) reforça a ideia de um patrimônio sentido e vivido, ou seja, que tenha significado e se vincule com a identidade local.

Vislumbrar a história da colonização de Itapiranga é olhar para um valor comunitário muito significativo e relevante, aspecto que caracteriza o ideal de formação de uma comunidade étnica e confessionalmente homogênea. Na visão de Werle (2011) a constituição da área colonizada em comunidades "criou um profundo sentimento comunitário e religioso, que foi determinante para a edificação de estabelecimentos escolares, religiosos e sociais sustentados por uma rede de associações, o que encobria a ausência do Estado nas regiões colonizadas" (Werle, 2011, p. 257). Nessa perspectiva, Werle (2011) também entende que os núcleos comunitários de Itapiranga foram projetados para acolher variadas formas associativas da comunidade, como igreja, clube, escola, cemitério e áreas de lazer. "Na genealogia dos valores, o zelo pela vida comunitária constituiu-se num valor supremo" (Werle, 2011, p. 257).

A partir dessa dimensão concordamos com Eidt (2009) e Mayer e Neumann (2016), no sentido de que os espaços de referência comunitária desempenharam um papel significativo na gênese histórica local. O esforço pela edificação de espaços públicos, construção de igrejas, construção de escolas, construção de centros de assistência social foram muito significativos para o desenvolvimento local, sendo um aspecto caracterizador da história, consequentemente, criando vínculos com a identidade histórica. Dessa forma, as edificações e os espaços que elencamos nesse estudo se justificam e se legitimam perante o contexto cultural e de memória. 


\section{AS EDIFICAÇÕES E SEU CONTEXTO}

As edificações históricas se inserem num contexto histórico e cultural que vincula o presente com o passado, criando laços de identidade e memória, servindo como referencial e significando a arquitetura no seu contexto cultural. Essas edificações se inserem no conceito de monumento, aspecto problematizado por Choay (2001) como sendo um edifício que adquire um valor com o passar dos anos por aquilo que ele representa para a sociedade.

Em Itapiranga não há uma edificação tombada legalmente como patrimônio, o que de fato legitima a relevância dessas edificações porque elas continuam sendo preservadas pela comunidade e, além disso, ainda possuem funcionalidade e estão inseridas no cotidiano do município. As edificações selecionadas para este estudo representam e sintetizam o valor de comunidade e coletividade, aspecto contextualizado e legitimado na análise histórica e de sua representatividade. Além delas, no contexto do espaço urbano e rural, existem outras inúmeras residências de valor histórico e patrimonial de propriedade privada.

Com base nesse critério de seletividade, apresentamos o seguinte quadro com uma breve descrição de cada edificação:

Quadro 1 - Edificações de relevância patrimonial do centro histórico de Itapiranga

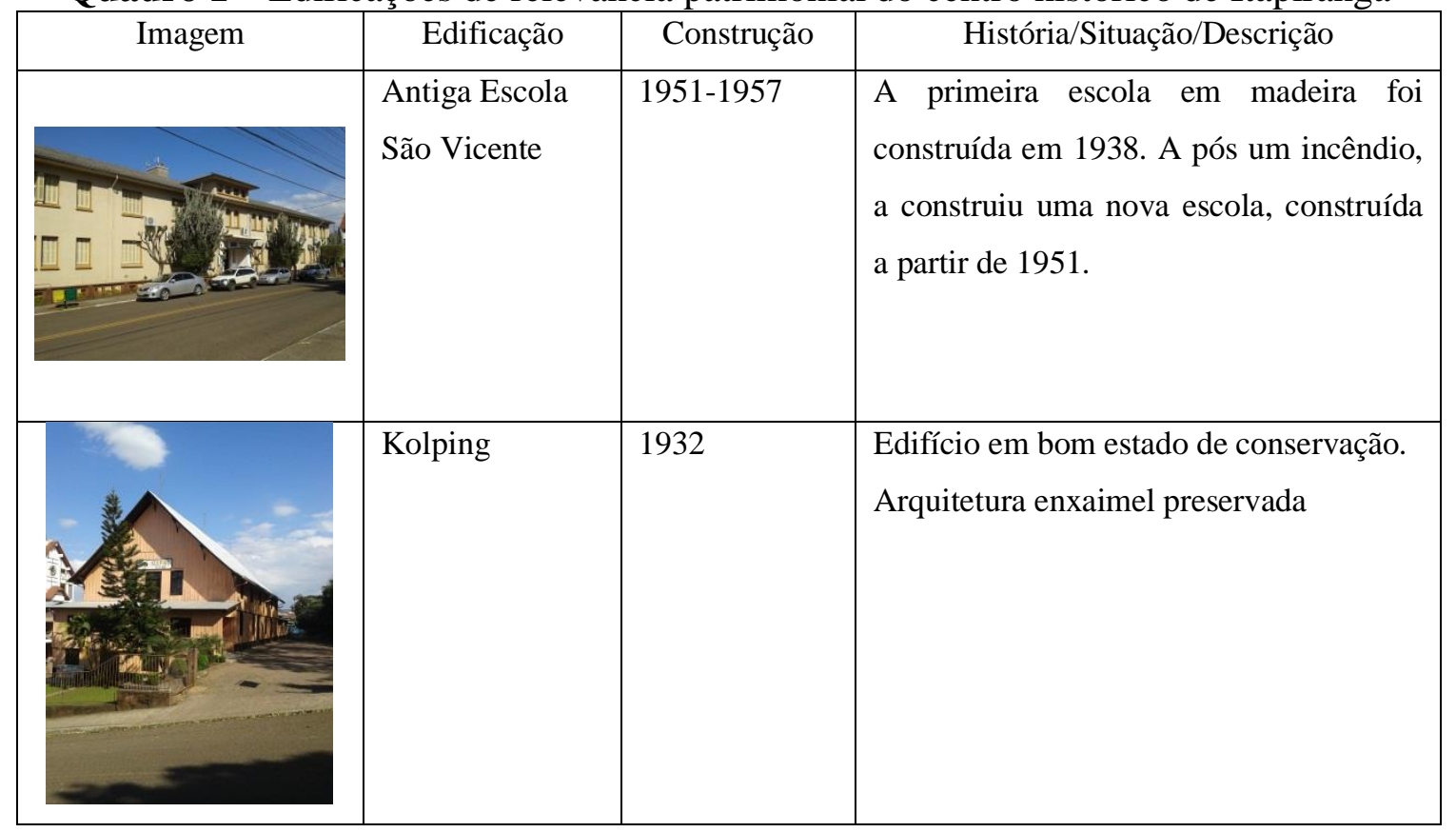




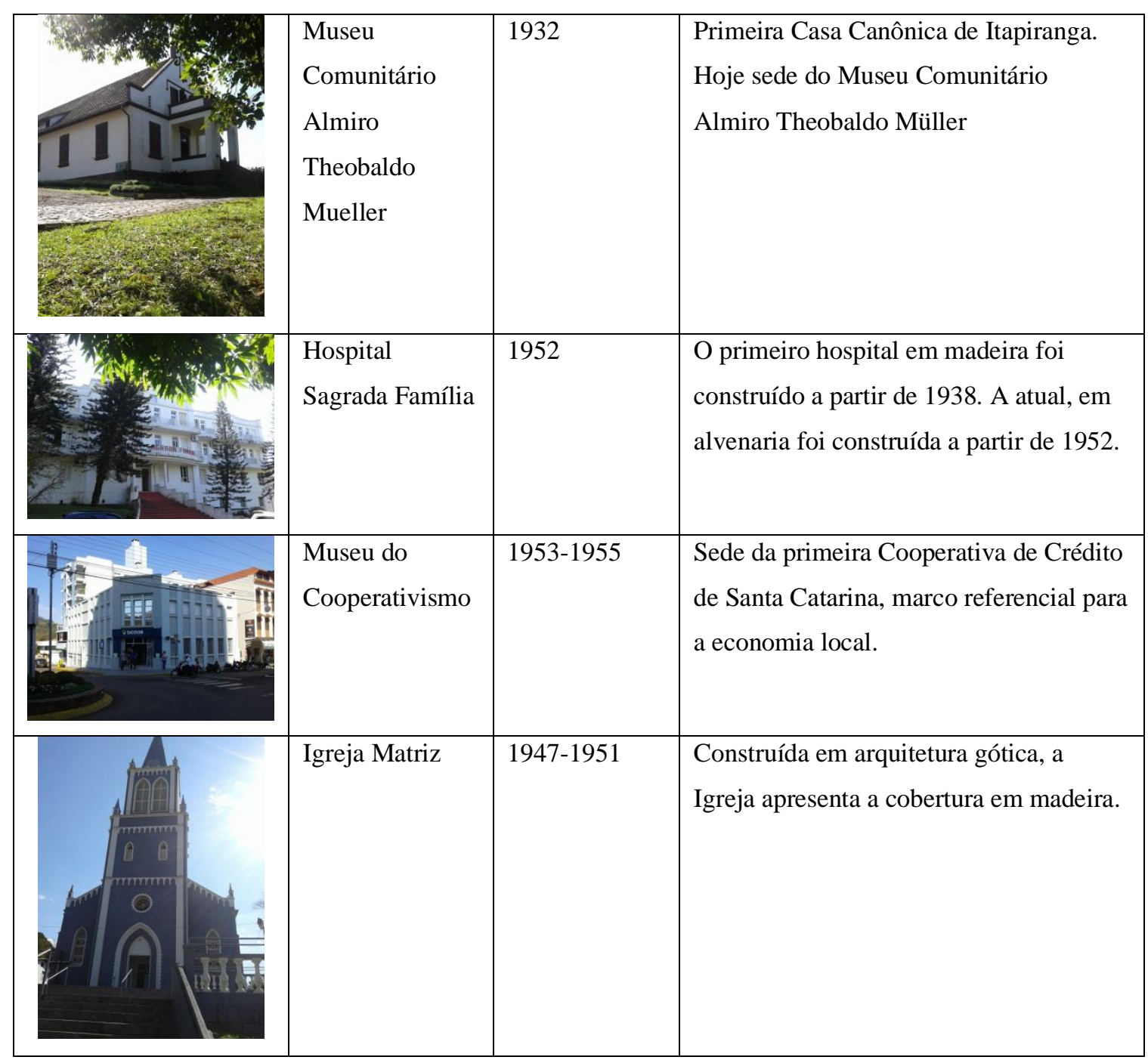

Fonte: Elaborado pelos autores, 2019.

As edificações selecionadas sintetizam a dinâmica histórica local a partir da reflexão sobre a importância que os espaços sociais e comunitários adquiriram no desenvolvimento local. Conforme Possamai (2001), no espaço urbano se manifestam rupturas e continuidades, onde a sociedade constrói a memória cultural tanto na manifestação material e imaterial do espaço urbano. "Essa memória não é estática, nem imutável, nem se restringe a fato e artefatos excepcionais" (Possamai, 2001, p. 17). Na verdade, no cotidiano se tecem relações de valor e identidade que significam a cultura local, dimensionadas através do patrimônio e do seu significado para o contexto.

A antiga Escola São Vicente representou um espaço significativo para o contexto local, sendo que a escola foi muito valorizada desde o princípio da colonização através da referência que a educação teve para as famílias. A primeira escola do núcleo colonial de Itapiranga foi construída pelas Irmãs da Divina Providência em 1938. Após um incêndio que acometeu a edificação em madeira, a comunidade optou em construir uma nova escola, em 
alvenaria e em escala maior. Essa escola serviu como internato para a congregação da Divina Providência e de escola para a comunidade regional. A Escola São Vicente como ficou conhecida, representou um elemento muito importante para a história de Itapiranga e está presente na memória dos inúmeros estudantes que nela estudaram (Mayer, 2018). Atualmente a edificação preserva sua arquitetura original e pela sua monumentalidade expressa um referencial histórico expressivo no contexto do espaço urbano. Atualmente estão instalados nesse prédio órgãos do Governo do Estado de Santa Catarina e a escola de música da Orquestra de Violões de Itapiranga.

O Clube Kolping foi construído no ano de 1932 com o objetivo de servir como espaço de convivência e sociabilidade comunitária. Fundado pelo Grêmio Católico de Artífices, visou fomentar na população as ideias do catolicismo social tão em voga em colônia alemãs no Sul do Brasil e também na Europa, numa referência a disseminada obra de Adolf Kolping, que valorizava os valores da comunidade, do assistencialismo social, do desenvolvimento econômico alicerçado nos ideais do catolicismo social, servindo como espaço de recriação de valores e de cultura, de trabalho, de comunidade, de associativismo e de recreação (Werle, 2007). O Clube é reconhecido pela comunidade local pela sua relevância histórica e arquitetônica, sendo utilizado ainda na atualidade para bailes, encontros comunitários e festividades. Por se tratar de uma edificação toda em madeira, apresenta a estrutura em enxaimel, o que potencializa sua relevância no contexto do centro histórico.

O Museu Comunitário Almiro Theobaldo Müller, construído em 1932 para servir de Casa Canônica para a Paróquia São Pedro Canísio, foi a primeira edificação em alvenaria construída em Itapiranga. Projetada pelo arquiteto jesuíta Francisco Gellerman, foi construída através do trabalho comunitário da população local. Devido à relevância do fator religioso e a importância que os jesuítas desempenharam na história local, a Casa Canônica foi um espaço muito simbólico para a comunidade católica. Atualmente a edificação abriga o museu, espaço de memória e de acesso público, onde se promovem exposições, atividades culturais e educativas.

O Hospital Sagrada Família teve sua construção iniciada em 1938, inicialmente em madeira e a partir de 1952 a edificação foi sendo gradativamente ampliada em alvenaria. O hospital representou um marco para a história de Itapiranga por representar um elemento de referência para o tratamento de enfermidades da população. Pela sua simbologia, possui um significado para a memória do município. Atualmente a edificação apresenta uma arquitetura monumental e de relevância para a paisagem da cidade e continua sendo uma referência em 
termos de assistência à saúde, vinculando passado e presente através da arquitetura e de sua funcionalidade social.

A Igreja Matriz da Paróquia São Pedro Canísio foi construída entre 1947 e 1951 em substituição à antiga igreja em madeira. Sua arquitetura apresenta referências góticas manifestas na sua composição. Contextualizamos a relevância do catolicismo para a formação da identidade histórica local e por isso a igreja possui uma simbologia para a paisagem e para a memória de Itapiranga. Pela sua verticalidade, se destaca na paisagem da cidade e potencializa a relevância do centro histórico para o conjunto urbano.

O Museu do Cooperativismo está localizado na sede da cooperativa de crédito mais antiga do Estado de Santa Catarina, fundada em 1932, com a denominação de Caixa Rural União Popular. Esta cooperativa foi muito significativa para a história de Itapiranga, sendo o cooperativismo é um elemento vinculado à história e a memória da formação e do desenvolvimento da colonização de Itapiranga, pois aglutinou o capital social da colônia em prol do seu projeto de desenvolvimento. Atualmente o Museu do Cooperativismo agrega essa memória cooperativista e da importância do capital social para o contexto histórico.

Essas edificações formatam o que propomos ser o centro histórico de Itapiranga, a Stadtplatz, a cidade preexistente com potencial visual e focal para o contexto urbano. Somamse a elas residências históricas que ainda estão presentes no cenário da cidade, muitas delas mantidas e preservadas por várias gerações, e outras a mercê da depredação e da degradação por falta de manutenção e restauração. Além disso, no espaço delimitado podemos encontrar espaços públicos de relevância como a Praça do Imigrante onde foi realizada a primeira missa e onde se preserva a memória das famílias colonizadoras e da herança indígena muito relevante para a história local, a Praça das Bandeiras, a Praça Nereu Ramos, o memorial do Pe João Rick que é muito significativo para a memória dos jesuítas e sua relevância histórica. Outros elementos se conectam com a paisagem e dão embasamento para o caráter singular do centro histórico como é o caso da árvore de cinamomo plantada em 1931 situada em frente à Igreja Matriz, a Gruta Rainha da Paz e a Gruta de Virgem Maria em frente ao Museu. Ou seja, variados elementos dão embasamento para que se possa constituir territorialmente um mapeamento do que se configura como o centro histórico de Itapiranga.

A partir disso, propomos o seguinte mapeamento das edificações do centro histórico com a sua referida localização. 


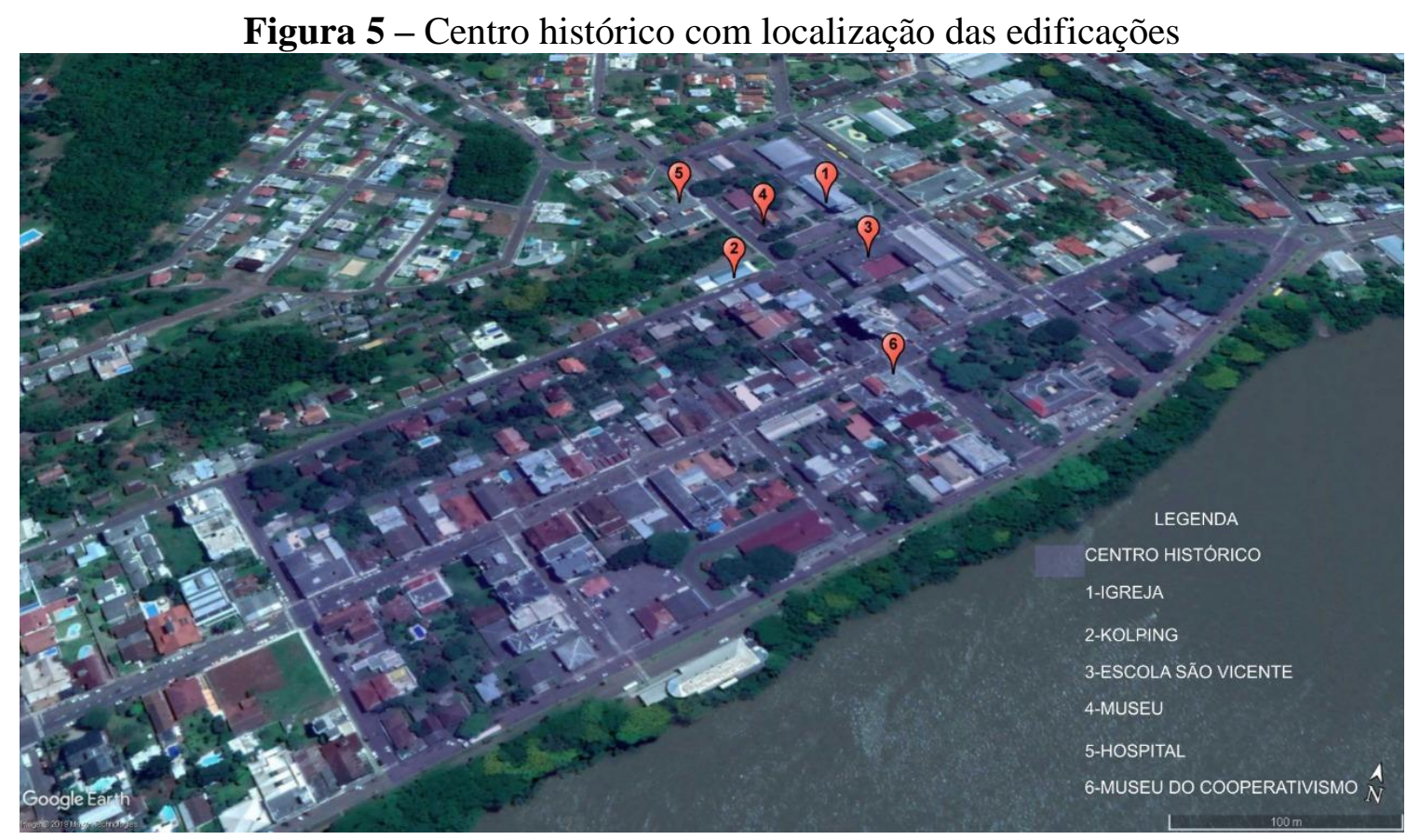

Fonte: Google Earth, adaptado pelos Autores, 2019.

Podemos perceber que as edificações históricas se localizam num núcleo formador com uma territorialização bem definida, manifestando o antigo padrão comunitário escolaigreja-clube. A partir disso podemos concluir que nesse espaço se formato o núcleo irradiador do centro histórico, a Altstadt, ou cidade antiga, elemento muito comum e valorizado nas cidades históricas da Alemanha, por exemplo.

O que se pretende apresentar nessa análise é de que o centro histórico é o espaço da cidade de Itapiranga que dispõe de recursos edificados que potencializam sua historicidade. Se formos pensar práticas de turismo ou de estímulo e valorização da memória, é preciso levar em consideração esse elemento e o que ele representa para o contexto cultural e turístico.

Como nenhuma dessas edificações é tombada oficialmente como patrimônio material, elas estão imunes ao abandono e à deterioração. Por isso é de extrema importância que elas continuem sendo utilizadas pela comunidade o que justificaria manutenções preventivas e restaurações. 


\section{O CENTRO HISTÓRICO E O SEU POTENCIAL TURÍSTICO}

O patrimônio histórico e cultural é um elemento que precisa ser valorizado pelo seu potencial educativo, reflexivo e de memória. Ele cria vínculos entre o passado e o presente, dá sentido para a cultura e significa o desenvolvimento humano com o contexto espacial. A Recomendação de Paris de 2003 fortalece a compreensão da profunda interdependência entre o patrimônio cultural imaterial e o patrimônio material cultural e natural, aspecto que se precisa levar em consideração quando buscamos compreender a dimensão do centro histórico de Itapiranga e seu potencial para práticas de turismo (Recomendação de Paris, 2003).

Não se podem pensar edificações históricas sem considerar a sua relação com as vivências, com as tradições, com os modos de viver, com os vínculos culturais e memoriais. A edificação é um produto da cultura humana, do saber fazer e que historicamente atende a uma necessidade ou funcionalidade, sendo objeto de uso para as atividades humanas. Dessa forma, o que se pretende não é desconectar as edificações históricas e muito menos o centro histórico do contexto cultural da cidade de Itapiranga. A cidade é um organismo vivo que precisa se relacionar em suas variadas dimensões.

Pelo seu valor arquitetônico e cultural, o centro histórico representa um espaço propício para políticas e práticas de turismo. A partir do momento em que o centro histórico se potencializa diante do fator turístico, consequentemente se manifesta a relevância dessas edificações para a geração de renda e movimentação da economia local. Como nenhuma das edificações é tombada como patrimônio material, o turismo pode ser um dos elementos que valorizem essas edificações perante o contexto urbano e social através vinculação com práticas turísticas.

Na concepção de Camilo e Bahl (2017), o turismo é um elemento significativo para o intercâmbio cultural, envolvendo um planejamento coerente e responsável por parte das comunidades receptoras e consequentemente a experimentação e a compreensão da cultura de uma localidade por parte dos turistas. "Os fundamentos do desenvolvimento turístico devem pautar-se por critérios de sustentabilidade, considerando a questão ecológica a longo prazo, a viabilidade econômica e o equilíbrio ético, social e ambiental para as comunidades receptoras" (Camilo \& Bahl, 2017, p. 2).

Bahl (2004) elenca alguns elementos que precisam ser considerados quando se pretende aliar patrimônio e turismo. Dentre eles podemos destacar: identificação de potencialidades; políticas de preservação do patrimônio; realização de atividades de resgate da memória e da identidade da cultura local; delimitação de áreas ou espaços com ocorrência de 
edificações ou alguns elementos culturais e históricos de expressão e representatividade; Utilidade e reaproveitamento de edificações históricas; possíveis ações de tombamento; práticas de recuperação e restauração; criação de itinerários, eventos, passeios, atividades culturais, concursos de fotografias que valorizem as edificações e o espaço histórico; revitalização de bairros e ruas; estímulo à atividades culturais; criação de parques e espaços temáticos e memoriais.

Esses elementos servem como um referencial para vincular o centro histórico à atividades turísticas, conectando o espaço com atividades econômicas e culturais. Para tanto é necessário um planejamento conjunto e vinculado com os interesses sociais e empreendedores, atentando para a necessidade de se valorizar o centro histórico pela sua relevância urbana e cultural sem agredir ou criar um turismo que ameace as condições de sustentabilidade e vivência da população nativa. Da mesma forma é preciso ter um cuidado para que a ideia do estímulo ao turismo não acabe gerando uma busca sedenta por cultura como mercadoria, gerando efeitos considerados como danosos, como a cenarização das cidades, a busca por um fetichismo da cultura, a cultura como um bem unicamente de consumo e o desenraizamento dos turistas.

Nesse sentido, Itapiranga possui muitos desafios para significar o centro histórico no contexto do turismo. Talvez o primeiro desafio seja compreender o valor que esse espaço e as edificações possuem perante seu contexto histórico. O que se percebe é que as edificações estão inseridas no cotidiano da sociedade, abrigam atividades culturais, oficinas de arte e música, órgãos de governo, ou seja, fazem parte da vida da sociedade. Essa realidade é muito positiva, mas pode ser um entrave para a prática turística no sentido de se constituir uma logística de visitação. A antiga Escola São Vicente abriga órgãos de governo, a Igreja Matriz e o Clube Kolping sequer se mantêm abertos para visitações internas e o Hospital Sagrada Família não permite visitações em seu interior. Mas isso não desmerece a relevância do centro histórico, pois as edificações estão presentes e estão inseridas no cotidiano de Itapiranga, tem significado e se tornam genuínas.

Outra deficiência detectada é a escassez de sinalização e orientação turística no centro histórico. Há poucas placas de orientação, nenhuma referência ao centro histórico, não se encontram elementos que descrevem determinada edificação, como totens, balizadores indicativos ou murais informativos. Ou seja, é muito pouco provável que o turista consiga identificar a relevância do centro histórico perante o contexto da cidade.

O grande desafio para a valorização do centro histórico numa perspectiva de turismo é dar sentido cultural e atrativo para as edificações históricas. Uma iniciativa que apresenta um 
potencial em Itapiranga é o "Dia D Deutschland", evento criado pela Prefeitura Municipal agregando em determinados dias do ano atividades alusivas à cultura germânica no município. A ideia é de que todo primeiro Sábado de cada mês o comércio e os restaurantes ofereçam produtos alusivos à cultura germânica além da organização de atividades culturais na Praça do Imigrante, espaço muito simbólico da história local, onde se encontra o memorial de fundação da colonização em 1926. A programação desse evento precisa referendar e conectar o centro histórico com as práticas culturais celebradas nesse dia, podendo ser através de oficinais temáticas, atividades culturais, oficinas, artesanato ou exposições temáticas.

Para fins de visualização do centro histórico e da paisagem proporcionada pelo Rio Uruguai, o Mirante do Bairro Bela Vista representa um elemento que necessitaria de uma revitalização e requalificação no contexto da cidade. A paisagem perceptível desse espaço potencializa o centro histórico destacando as edificações perante o contexto da cidade e a sua conexão com o Rio Uruguai. Buscamos evidenciar na imagem a perspectiva que se tem do centro histórico a partir da vista do Mirante, bem como a referência ao leito do Rio Uruguai no contexto da paisagem da cidade. Percebe-se que o centro histórico não constitui um elemento claro e perceptível através das referências das edificações, sendo ofuscado por edificações mais contemporâneas e mais verticalizadas. A requalificação do centro histórico e a necessidade de se planejar a referência arquitetônica das edificações históricas é um elemento que precisa ser valorizado nas políticas urbanas de Itapiranga.

Figura 6 - Vista do Mirante do Bairro Bela Vista com realce do centro histórico

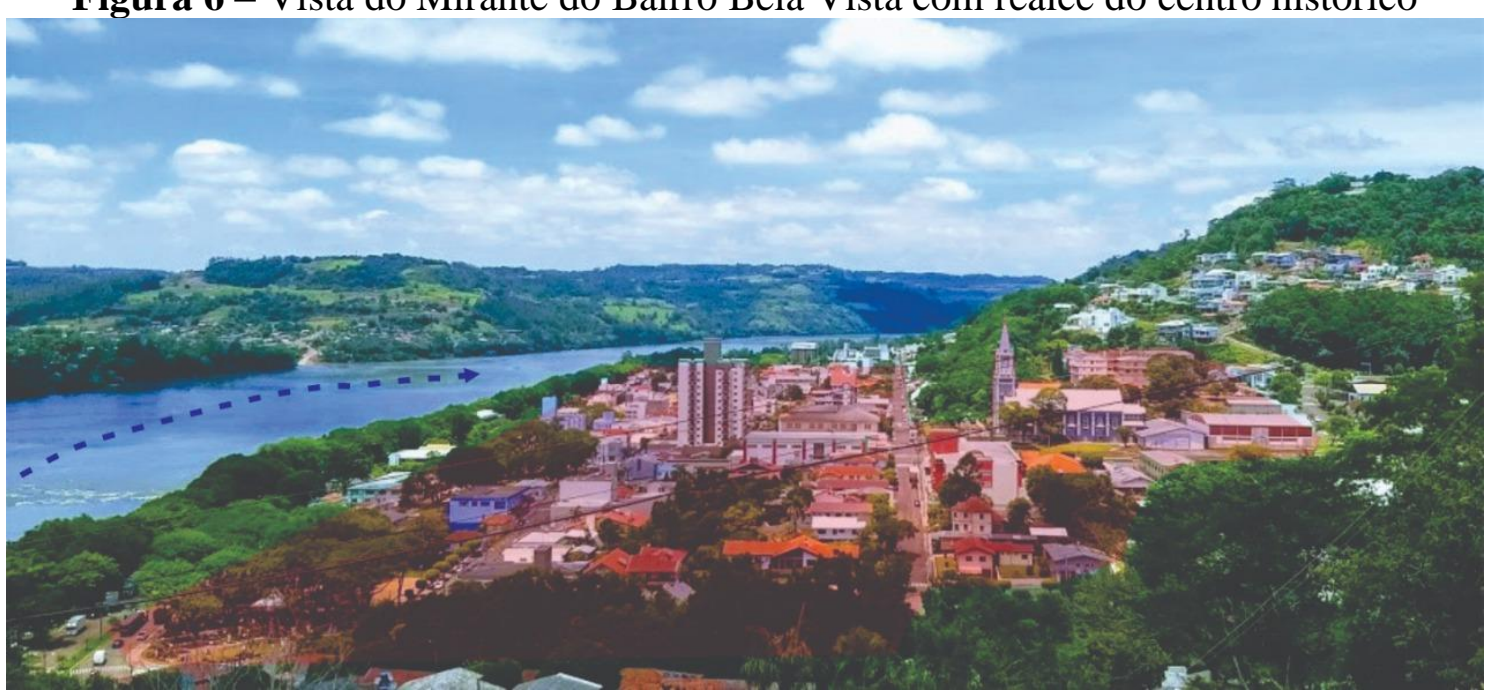

Fonte: Portal do Turismo de Itapiranga. Adaptado pelos autores, 2019.

Na Imagem 06 temos uma perspectiva da paisagem urbana de Itapiranga com o Rio Uuguai e o centro histórico em destaque, com a Igreja Matriz em primeiro plano e o Kolping, o Hospital Sagrada Família e a Escola São Vicente em segundo plano. Os elementos 
apontados se tornam marcos referenciais para a paisagem, o que Lynch (1999) denominou de pontos nodais e focais marcantes para a percepção espacial da cidade. Na visão de Lynch (1999), a imagem da cidade é construída subjetivamente pelo observador e precisa de referências para fazer sentido, sendo a relação com o contexto significativo para constituir a compreensão espacial e paisagística.

Na imagem da cidade que se constitui a partir do Mirante Bela Vista pretende-se significar a relevância desse espaço para a percepção do centro histórico, constituindo pontos focais através da arquitetura e das referências paisagísticas. O Rio Uruguai constitui um elo com o contexto, delimitando o espaço da cidade e referendando a paisagem. A paisagem é composta de elementos que vão além das edificações históricas selecionadas, formando-se a partir de muitos elementos e de espaços referenciais que constituem o centro histórico, como praças, locais de memória, espaços de recreação e lazer e vias de trafegabilidade.

No Mirante poderiam ser oferecidas informações sobre o centro histórico identificando as edificações e a representatividade desse espaço para o núcleo fundacional de Itapiranga, estimulando o turista a perceber o centro histórico e sua simbologia para o espaço.

\section{CONSIDERAÇÕES FINAIS}

O centro histórico se constitui num referencial para o contexto urbano, pois emana valores de identidade e representatividade memorial. A partir dele podem-se tecer compreensões da evolução da cidade e compreender elementos que colaboraram no desenvolvimento local. Nesse sentido, a Stadtplatz é representativa para Itapiranga, pois se constituiu na sede da colonização como referencial para as atividades comerciais, serviços de utilidade pública, atividades culturais, sociais, recreativas e educativas.

Tendo como base a ideia da relevância da compreensão do centro histórico, sem pretender desconectar ou sobrevalorizar esse espaço em detrimento do contexto da cidade, o texto buscou estabelecer uma reflexão sobre algumas edificações que ainda são preservadas nesse espaço e que refletem o valor de identidade comunitária e social para Itapiranga. Elas se manifestam arquitetonicamente na paisagem, se conectam com o cotidiano pela sua presença material e pela sua funcionalidade e utilidade que ainda desempenham para a vivência local.

O desafio que o texto propõe é de conectar o centro histórico ao potencial do turismo cultural, com o intuito de valorizar e qualificar o cetro histórico através de práticas de turismo e a partir disso tornar esse espaço relevante perante investimentos do setor privado e de planos de gestão e planejamento urbano. 
Essa preocupação se torna emergencial visto que recentemente a Prefeitura Municipal de Itapiranga regulamentou novas diretrizes para o zoneamento e a possibilidade de novas edificações na área de preservação (APP). Isso pode significar uma ameaça às edificações históricas visto à concorrência com projetos de construção de edifícios com maior número de pavimentos, realidade que necessariamente afetará a paisagem da cidade. A valorização do centro histórico através da vinculação ao turismo poderia ser um fator de conscientização sobre a necessidade de preservação desse espaço e valorização da paisagem a partir da história e da memória de cidade.

O centro histórico atualmente se conjectura com um espaço de vivências e representatividades pelas variadas conexões que são estabelecidas entre a dinâmica do espaço, as atividades sociais e culturais, atividades comerciais, dinâmicas da paisagem exponencializadas pela exuberância do Rio Uruguai. As edificações históricas aqui analisadas se conectam com outros inúmeros fatores, são funcionais, pois desempenham uma utilidade para a comunidade, vinculam cultura material e imaterial, dão sentido histórico e identitário para o cotidiano de Itapiranga.

\section{REFERÊNCIAS}

Bahl, M. (2004). Fatores ponderáveis no turismo: sociais, culturais e políticos. Curitiba: Pretexto.

Camilo, I., \& Bahl, M. (2017). Desenvolvimento do turismo baseado em elementos culturais. Revista Turismo e Sociedade, 10(1), 1-12.

Choay, F. (2001). A alegoria do patrimônio. São Paulo: Ed. UNESP.

Eidt, P. (2009). Os sinos se dobram por Alfredo. Chapecó: Argos.

Jungblut, R. (2000). Documentário Histórico de Porto Novo. São Miguel do Oeste: Arco Íris Gráfica e Editora.

Lynch, K. (1999). A Imagem da Cidade. São Paulo: Martins Fontes.

Mayer, L., \& Neumann, R. M. (2016). A dinâmica de ocupação e povoamento de Porto Novo: uma colônia étnica e religiosamente homogênea. Revista Brasileira de História e Ciências Sociais, 8, 73-88.

Mayer, L. (2018). Oitenta anos da Escola São Vicente (1938-2018). São Leopoldo: Oikos.

Mazzardo, S. C. (2017). Aspectos da evolução urbana de Itapiranga (SC): cidade nova e pequena. 287 f. Dissertação de Mestrado em Arquitetura e Urbanismo, Programa de Pós Graduação, Universidade Federal de Santa Catarina. Florianópolis, SC, Brasil.

Possamai, Z. (2001). A memória cultural numa cidade democrática. Porto Alegre: Editora Secretaria Municipal da Cultura de Porto Alegre. 
Recomendação de Paris. (2003). Convenção para a Salvaguarda do Patrimônio Imaterial. Unesco.

Roche, J. (1969). A colonização alemã e o Rio Grande do Sul. Tradução Emery Ruas. Porto Alegre: Editora Globo.

Scocuglia, J. B. C. (2004). Revitalização urbana e (re)invenção do centro histórico na cidade de João Pessoa (1987-2002). João Pessoa: Editora Universitária UFPB.

Seyferth, G. (2011). O colono múltiplo: transformações sociais e (re)significação da identidade camponesa. Revista Raízes, 31(1), 10-23.

Silva, M. A. (2014). Centralidades em movimento: a cidade contemporânea e o tempo histórico. In: Pimenta, M. C. A., \& Figueiredo, L. C. (Orgs.). Lugares: patrimônio, memória e paisagens. Florianópolis: Editora da UFSC.

Trusiani, E. (2004). Do centro histórico à cidade histórica: a dimensão do projeto de conservação - o caso da cidade de Roma. Revista Desenvolvimento e Meio Ambiente, (9), 101-106.

Woortmann, E. (1994). Herdeiros, parentes e compadres. São Paulo: Hucitec.

Werle, A. C. (2011). Porto Novo: o reino jesuítico germânico no oeste de Santa Catarina. Curitiba: CRV.

Werle, M. J. (2007). A formação das comunidades Kolping de Itapiranga e Rio do Sul. 134 f. Dissertação de Mestrado em História, Universidade Federal de Santa Catarina, Florianópolis, SC, Brasil.

Zanirato, S. H. (2018). Patrimônio e identidade: retórica e desafios nos processos de ativação patrimonial. Revista CPC, 13(25), 7-33.

FORMATO PARA CITAÇÃO DESTE ARTIGO

FRANZEN, D. O, BADALOTTI, C. M., \& CHAVES, G. C. (2020). Uma análise histórica a partir da Stadtplatz (Centro histórico) de Itapiranga e sua relação com o turismo cultural. Revista de Turismo Contemporâneo, 8(2), 293-315. https://doi.org/10.21680/2357-8211.2020v8n2ID19491 